\title{
Food Sharing, Redistribution, and Waste Reduction via Mobile Applications: A Social Network Analysis
}

John Harvey, Andrew Smith, James Goulding, and Ines Branco-Illodo

\section{Highlights}

- The study presents a longitudinal social network analysis of 54913 food sharing instances mediated by mobile applications

- Analysis reveals that the platform encourages and blurs different forms of supply chain including B2C, C2C and B2V2C (Business to Volunteer to Consumer)

- The results demonstrate that network members typically perform different roles as either donors or recipients and that the regularity of use also varies dramatically

- Reciprocity is extremely rare between members, but there are nonetheless connected components and interdependencies within the network

Accepted refereed manuscript of: Harvey J, Smith A, Goulding J \& Branco Illodo I (2020) Food Sharing, Redistribution, and Waste Reduction via Mobile Applications: A Social Network Analysis. Industrial Marketing Management, 88, pp. 437-448.

https://doi.org/10.1016/j.indmarman.2019.02.019

(c) 2019, Elsevier. Licensed under the Creative Commons Attribution-NonCommercial-NoDerivatives 4.0 International

http://creativecommons.org/licenses/by-nc-nd/4.0/ 


\title{
Food Sharing, Redistribution, and Waste Reduction via Mobile Applications: A Social Network Analysis
}

\begin{abstract}
Food sharing mobile applications are becoming increasingly popular, but little is known about the new social configurations of people using them, particularly those applications that use consumers as voluntary intermediaries in supply chains. This article presents a social network analysis of a food sharing mobile application conducted in partnership with OLIO. The study focuses on longitudinal social network data from 54913 instances of food sharing between 9054 people and was collected over 10 months. The results challenge existing theories of food sharing (reciprocity, kin selection, tolerated scrounging, and costly signalling) as inadequate by showing that donor-recipient reciprocity and balance are rare, but also show that genuinely novel social relations have formed between organisations and consumers which depart from traditional linear supply chains. The findings have significant implications for managers and policymakers aiming to encourage, measure and understand technologyassisted food sharing practices.
\end{abstract}


Food Sharing, Redistribution, and Waste Reduction via Mobile Applications: A Social Network Analysis

\section{Corresponding Author}

Dr John Harvey is an Assistant Professor of Marketing at the University of Nottingham

Email: john.harvey2@nottingham.ac.uk

Phone: Tel: +44 (0) 1158466675

\section{Other Authors}

Professor Andrew Smith is a Professor of Consumer Behaviour at the University of Nottingham and the Director of the Neo-Demographics Lab - a research centre focussing on international analytics for social good.

Email: Andrew.P.Smith@nottingham.ac.uk

Dr James Goulding is an Assistant Professor in Analytics and Deputy Director of the NeoDemographics Lab

Email: James.Goulding@nottingham.ac.uk

Dr Ines Branco is a Senior Lecturer in Marketing at Nottingham Trent University.

Email: ines.brancoillodo@ntu.ac.uk 


\title{
Food Sharing, Redistribution, and Waste Reduction via Mobile Applications: A Social Network Analysis
}

\begin{abstract}
Food sharing mobile applications are becoming increasingly popular, but little is known about the new social configurations of people using them, particularly those applications that use consumers as voluntary intermediaries in supply chains. This article presents a social network analysis of a food sharing mobile application conducted in partnership with OLIO. The study focuses on longitudinal social network data from 54913 instances of food sharing between 9054 people and was collected over 10 months. The results challenge existing theories of food sharing (reciprocity, kin selection, tolerated scrounging, and costly signalling) as inadequate by showing that donor-recipient reciprocity and balance are rare, but also show that genuinely novel social relations have formed between organisations and consumers which depart from traditional linear supply chains. The findings have significant implications for managers and policymakers aiming to encourage, measure and understand technologyassisted food sharing practices.
\end{abstract}

\section{Keywords}

Food sharing, Food Waste, Altruism, Reciprocity, Social Network Analysis, Sharing Economy

\section{Introduction}

Food sharing and redistribution is a common feature of societies (Jaeggi \& Gurven, 2017) but the way people share and redistribute food is changing. The emergence of food sharing websites and mobile applications have the potential to radically disrupt food commodity lifecycles from production through to disposal (Falcone \& Imbert, 2017). Peer-to-peer (P2P) technology appears to frame food waste as an optimisation problem; a simple inefficiency created by a lack of consumer coordination. In reality we know very little about the anatomy of such systems of redistribution. As Davies et al., (2017, p.136) note, "there has been little examination of the role that emerging information and communication 
technologies (ICT) are having on food sharing, despite claims that such technologies offer transformative potential to achieve more secure, sustainable and just food systems."

Increasingly, consumers and businesses are under social pressure to eradicate food waste. Waste is widely seen as a moral issue, not only from an environmental perspective, but also in terms of economic justice (Ciaghi \& Villaflorita, 2016). The largest contribution to food waste in the UK comes from homes: 8.3 million tonnes per year, which costs consumers $£ 12$ billion and contributes to approximately $3 \%$ of UK greenhouse gas emissions (Quested et al., 2011). The consequence of a growing social awareness of food waste and the ethical consequences associated with it have led to a variety of alternative food provision schemes being launched online and offline, sometimes referred to as Alternative Food Networks or AFNs (Goodman et al, 2012; Edwards, 2016). AFNs include a broad range of activities including farmers' markets, community-supported agriculture, box schemes, solidarity-based purchasing groups, food hubs, urban agriculture, and community gardens (Matacena, 2016). Many new initiatives aim to tackle the paradox that billions of tonnes of food are wasted annually yet many people still go hungry.

Some initiatives have a simpler aim to redistribute excess production directly to consumers or via intermediaries throughout the supply chain. "There has been plenty of discussion in the mainstream business press about how digital technologies are transforming companies' business models and customer-facing activities. But what's discussed less widely is how those technologies are also transforming companies' supply chains" (Monahan and $\mathrm{Hu}, 2015,96)$. These reconfigurations of supply can result in a blurring of traditional B2B and B2C roles and responsibilities, particularly when consumers take on responsibility for the provisioning of other consumers (C2C). For food consumption, like many other areas of the economy, sharing and access-based consumption practices are transforming traditional business models and upending producer-consumer relations (e.g. Botsman and Rogers 2010; Breitsohl et al. 2015; Bucher et al. 2016; Harvey et al, 2018; Hellwig et al. 2015; Lamberton and Rose 2012; Scaraboto 2015; Schor and Fitzmaurice 2015; Watkins et al. 2016). Existing research on supply chain management has considered information technologies, such as collaborative platforms, as separable from business relationships, thus neglecting how those platforms relate to buyer-supplier 
relationships and networks (Makkonen \& Vuori, 2014). Academic understanding of how participants in $\mathrm{P} 2 \mathrm{P}$ sharing networks interact with each other often hinges on the assumption of 'generalised reciprocity' between users, but limited empirical evidence is available to substantiate such claims. Network analysis techniques have been used recently to study the transformation of B2B markets using digital technologies (Pagani\&Pardo, 2017) but as far as we know, these same methods have not been used to study P2P food sharing networks.

The study reported in this article examines how a popular food sharing mobile application named OLIO has resulted in a tremendous reduction in food waste in the UK by reconfiguring traditional supply chain roles of consumers. It is crucial to note that OLIO operates as a pro-social actor on a commercial for profit footing. A social network analysis illustrates how new social configurations are transforming food provision for hundreds of thousands of people in ways that break the traditional B2C model where food is simply purchased as a commodity.

The theoretical contributions of the paper are threefold: (1) the results challenge previous claims that food sharing between non-kin is based on generalised reciprocity; (2) network analysis reveals that the OLIO network has supported the emergence of anarchistic food sharing practices characterised by bidirectional (albeit not balanced or reciprocal) flows between users at an individual user and volunteer level; and (3) the findings challenge the assumption that we can readily generalise about the anatomy of sharing in the digital era (since a key determinant is the design of the P2P platform). This raises an important methodological point: If the anatomy and manifestation of the long-standing elements of sharing (e.g. reciprocation) are fluid and subordinate to the platform and managerial structure, then descriptive forms of analysis such as social network analysis are essential for scholarly insight and managerial decision making alike.

After this introduction, in the second section we outline the motivational drivers of food sharing identified in previous social science research. We introduce the research context, including poverty and waste as situational determinants of new food sharing initiatives in the UK, and OLIO as a case study for studying food sharing. In the third section we discuss the research approach which consists of a longitudinal social network analysis of interactions between users. In the fourth section we present an 
exposition of the findings and discuss the results. Finally, in the fifth section we highlight key theoretical contributions and implications for practitioners/policy makers and conclude with the research limitations and agenda for future research.

\section{Theoretical background and research context}

\subsection{Motivational drivers of food sharing}

Food sharing, sometimes referred to as commensality (literally: eating at the same table), is a common behaviour enacted by primates (Jaeggi \& Gurven, 2013; Jaeggi \& Van Schaik, 2011), eusocial insects, social carnivores (lions, wolves, wild dogs), ravens and vampire bats, and yet sharing food between humans occurs with a complexity unlike any other organism (Kaplan \& Gurven, 2005). Humans learn food sharing practices as children (Birch \& Billman, 1986), first as beings dependent on the partaking of milk, later through the division of communal meals, and for many people these relations become bidirectional as they give and take well into their adolescence and adult years. Archaeological records reveal that food sharing and storing practices vary widely, but they have nonetheless been a consistent feature of human sociality for thousands of years (Enloe, 2003). Present-day anthropological records similarly reveal a huge variety of food sharing arrangements across the world, in both developed and developing countries, among industrialised and forager peoples, within and beyond the nuclear family kinship group.

Historical analysis reveals that hierarchical food sharing between social classes in the UK has occurred repeatedly, at least since the feudal era where communal feasting occurred regularly (Goody, 1982). Interhousehold food sharing in egalitarian societies has been shown to reduce risk (Hegmon, 1991). Indeed, food sharing beyond immediate kin is widely documented in humans and other species but has been explained with recourse to a range of competing accounts (Stevens \& Gilby, 2004). Four ultimate motivations for why people share food are regularly cited in the anthropological literature, these include: reciprocal altruism, kin selection, costly signalling, and tolerated scrounging (in opposition to unsolicited giving) (Jaeggi \& Gurven, 2017). 
Food is commonly shared in the family context (Jaeggi \& Girven, 2013), but kin selection is not obviously at play in the case of OLIO as the vast majority of interactions happen between people that are previously unfamiliar. Tolerated scrounging is the idea that people take food from others without having something to offer in return and that this behaviour is accepted in moderation (Gurven, 2004). Though the assumptions of tolerated scrounging have been questioned (Brown, 2004) it is often put forth as a causal argument by behaviourists, but also in contrast demand sharing has also been argued to be an important social and symbolic practice too (Peterson, 1993), where social prestige can arise from sharing. The social consequence of sharing food can therefore be extended as an example of costly signalling, wherein the person sacrificing their wealth through sharing accrues an evolutionary benefit by demonstrating their relative fitness. An argument of tolerated scrounging and costly signalling in relation to OLIO would, like kin selection, be inadequate to explain the food sharing exhibited by users in that the food shared is not solicited by familiar people, it is instead generously initiated by donors in relation to strangers.

Jaeggi \& Gurven (2013b) suggest that reciprocity explains food sharing independent of kin selection or tolerated scrounging. Reciprocal altruism posits that a reciprocal arrangement of food sharing between two non-kin individuals would reduce the dangers in their environment, thus this altruistic behaviour increases their chances of survival (Trivers, 1971). Social exchange and reciprocity have been used extensively to explain the underlying motivations for the sharing economy assuming that, material exchanges are fundamental for social interaction and require reciprocity (Guyader, 2018; Kumar, Lahiry \& Dogan, 2018). Reciprocity is normally described as being 'generalised' (following Sahlins, 1979) in that it is not obligatory but that the flow of material transactions will tend to equalise over time (Guyader, 2018). However, in the context of food sharing, cooperation is not restricted to bilateral interactions and reciprocity is complex as there are third parties that can reward or punish those violating food sharing norms (Fehr \& Fischbacher, 2003). Indeed, various anthropologists have critiqued the usefulness of the reciprocity concept for explaining non-monetary economic behaviour (Pryor and Graburn, 1980; Ingold, 1986; Hann 2006; Graeber 2014; Widlok, 2017) instead favouring localised descriptions of food sharing practices that are sensitive to situational determinants. Similar motivational drivers of food sharing are 
found for people around the world, but the behaviour is nonetheless heavily influenced by situational determinants, such as political economy and food scarcity. In the following section we provide an overview of two significant factors driving food sharing in the UK: waste and poverty.

\subsection{Waste and poverty as situational determinants of food sharing in the U.K.}

Charitable foodbank use in the UK has risen rapidly over the past two decades (Lansley \& Mack 2015). The Trussell Trust alone distributed 1,182,954 instances of emergency 3-day food supplies between April 2016 and March 2017 (Trussell Trust, 2017). This staggering increase is not merely from people experiencing financial hardship due to a lack of employment. The growing number of people experiencing 'in-work' poverty has increased foodbank use as salaries fail to cover basic expenditure. But many people are still reluctant to visit foodbanks, with previous research indicating that the experience is often coupled with negative emotions such as guilt, shame, embarrassment or a feeling of indebtedness (Garthwaite, 2016a, 2016b). The growing food crisis in the UK has prompted cross-party political attention. Indeed, a recent report entitled "Feeding Britain, prepared by an All-Party Parliamentary Inquiry into Hunger in the United Kingdom, acknowledged that there was a significant number of hungry people and ... the terrifying idea that hunger is here to stay unless all of us take our responses on to a new and totally different level" (APPIHUK 2014, p. 8)"

The growing demand for alternative food provision has spawned a variety of initiatives which reimagine how food is commoditised and distributed through supply chains. This reimagining is most apparent in supply chains with excessive food waste, particularly supermarkets with regular daily surpluses which can be redirected and repurposed en masse. For instance, the UK organisation FareShare is responsible for collecting and distributing food surpluses to a wide variety of charity organisations such as "pay what you feel' and 'social eating' cafes. According to Baron et al (2018, p.138) "this is a significant operation: In 2016, over 5,000 charities/ community groups received food from FareShare. Some 25 million meals were provided from the 12,000 tons of food which were processed". Baron et al (2018) suggest these initiatives are part of a broader 'feed people first' movement which aims to guide the effective redirection of edible food waste to those citizens suffering from hunger. 
Some authors have suggested that food waste is a distinct concept from food loss (Bloom, 2010; Buzby \& Hyman, 2012). Food loss is a "drop in the food supply due to a reduced nutrient value of the food or to a decrease in its weight or volume". Food waste can be defined as a state in which edible food goes uneaten because of a supply chain inefficiency, these can be the result of decisions made by consumers, supply chain actors or other stakeholders, and it represents a subset of total food losses. (Cicatiello et al. 2016). Although much of the blame for food waste is often directed at retailers, FarrWharton et al (2014a) suggest that three forms of consumer knowledge are often central to food being wasted, these include: 1) supply knowledge - does a consumer know what food they have available; 2) location knowledge - does a consumer know where to locate food items; and 3) food literacy - the degree to which experience and acquired knowledge influence a consumer's food consumption and wastage practices.

Digital innovations like OLIO (and others such as Ampleharvest.org, Foodsharing.de, and Casseroleclub.com) have attempted to influence all three forms of consumer knowledge. These new initiatives have led some authors to suggest that the sharing economy has the potential to disrupt food waste by reconfiguring consumption-production systems (Martin, 2016). In an "actor-bonds-centred type of digitalization", digital innovations like mobile apps can foster new relationships by creating connections between actors that were not connected before (Pagani \& Pardo, 2017, p.189). Although collaborative platforms enhance supply chain management opportunities, existing research focuses on operational issues, thus neglecting how platforms relate to broader supply chain networks and "buyersupplier" relationships (Makkonen \& Vuori, 2014). Although some research has looked at the impact of digital technology on relationships different from Business-to-Consumer (B2C) (Pagani \& Pardo, 2017), this happened in the context of Business-to-Business (B2B) exchanges rather than P2P sharing. Following this type of digitalisation, digital platforms such as OLIO enable the creation of bonds between food donors and recipients and transform consumers' food consumption and wastage practices.

With the development of ubiquitous computing devices such as tablet computers and mobile telephones there has been a recent upsurge in the number of people using websites and applications to share food. Academics too have suggested that effective human-computer interaction design may help to reduce 
both food waste and food poverty through sharing practices enabled by technology but have also noted that more research is needed to understand the social configurations which might enable such solutions (Ganglbauer et al., 2013; Clear et al, 2013). Indeed, “actors with different interests in food commodity chains actually develop competing solutions, both within and between three hierarchies based on environmental, social and economic goals" (Mourad, 2016, p.461). But the emergence of new P2P sharing systems nonetheless offers a pathway to "a new economy built around concern for people and the environment" (Martin, 2016, p. 154).

\subsection{Previous empirical work on technology-assisted food sharing}

Empirical studies to date on technology-assisted food sharing are varied in nature but all demonstrate the rapid increase in users on peer-to-peer $(\mathrm{P} 2 \mathrm{P})$ sharing systems. "P2P systems are those that enable two or more peers to collaborate spontaneously in a network of equals (peers) by using appropriate information and communication systems without the necessity for central coordination" (Plouffe, 2008; p.1182). Much of the existing research is design focused or comparative in nature, including designbased comparative research of food sharing mobile apps (Farr-Wharton et al., 2014b); thematic analysis of discussion posts on food sharing web pages (Ganglbauer et al, 2014); ethnographic research into shared food growing spaces (Harvey et al, 2017); survey research into the motivation of users of a Peerto-Peer (P2P) meal-sharing initiative for tourists (Ketter, 2017); and development of recommendation systems for P2P collaboration based on food available to consumers (Lim et al, 2017). Others have focused on the potential of technology for encouraging new forms of food sharing. Examples include designing P2P food sharing networks to assist older users that are reluctant to using software (Macik et al., 2015); and activist research aimed at designing novel peer-to-peer food sharing applications to understand the barriers to widespread adoption of such a system (Burton et al., 2017). Yet, recent research highlights that $\mathrm{P} 2 \mathrm{P}$ collaborative consumption practices require further research attention to understand what suppliers and consumers do in this context (Guyader, 2018).

In a recent exploratory study Michelini et al (2017) found 52 food sharing initiatives mentioned in academic literature. A hierarchical clustering analysis revealed that although there is a broad variety of design strategies there are nonetheless three loosely-related forms of initiative that encourage food 
sharing: (1) sharing for money i.e. to make a profit; (2) Sharing for charity i.e. sharing food with a nonprofit; and (3) sharing food for community, where consumers are primarily responsible for sharing food among themselves. OLIO was placed in the third category, although these are perhaps best thought of as fuzzy rather than discrete categories.

Although OLIO has been discussed briefly in previous work (Lewis, 2017; Carrigan, 2017), there are no existing empirical studies that quantitatively analyse the network of actors participating in food sharing, nor the relationships and supply networks in terms of "buyer-supplier" interaction (Makkonen \& Vuori, 2014). Furthermore, a search of the extant literature revealed no studies that empirically illustrate social network behavioural data for P2P food sharing services to: (a) show how these services are practically used by consumers to interact; and (b) explain the variance of user types that exist whether they are bound by reciprocal tit-for-tat exchanges, whether they act as brokers between groups, or whether they form asymmetrical dependence relations. The answers to these questions matter because they would help to provide empirical support (or contradiction) to the many motivations social scientists have claimed underpin food sharing. Although there is a wealth of research on food sharing from historical and cultural perspectives, there is a dearth of large-scale empirical evidence available on the behavioural patterns of food sharing services, particularly where the boundary between businesses and consumers becomes blurred. This is problematic because despite the high number of people using such services the behaviour that people enact is not known with any precision, nor whether any ultimate motivations are clearly demonstrable in practice. In the following section we introduce OLIO as a case study for empirically studying how people share food in practice rather than reaching $a$ priori conclusions.

\subsection{OLIO - A mobile application to encourage food sharing}

OLIO was founded by Tessa Cook and Saasha Celestial-One in February 2015. According to OLIO's website (OLIO, 2018) it is 'a free app that connects neighbours with each other and with local businesses so surplus food can be shared, not thrown away. This could be food nearing its sell-by date in local stores, spare home-grown vegetables, bread from your baker, or the groceries in your fridge 
when you go away.' Initially the application was developed for use in only five postcodes in London (U.K.), but after proof of concept and initial success the application was made available for download worldwide. At the time of writing the application has proved to be extremely successful and is the most popular food sharing mobile application ever created in terms of downloads. According to OLIO's statistics 512,010 people have registered and over 697,108 items of food have been shared across 41 countries (As of 27/09/2018).

OLIO is a private company rather than a non-profit, which is unusual for a prosocial exchange system (See Harvey et al, 2018), but this has not deterred volunteers from assisting OLIO in their campaign to reduce food waste - over 13,200 people have volunteered at the time of writing. Volunteers can take on qualitatively different roles in relation to OLIO. Some are encouraged to help advertise and promote the application, whereas others take a 'hands-on' approach and act as intermediaries between businesses and consumers. The latter category of volunteers are essentially trusted distributors for organisations. Volunteers help to ensure food is fairly and proportionally shared between recipients and ensure continuity of experience for collaborating organisations such as large supermarkets. OLIO's business model is still embryonic, but currently has revenue streams from commercial food waste reduction partnerships and is also developing towards a 'freemium' version of the mobile application. 
The application is available to download on Android and Apple mobile phones. Registration is simple and requires email or the use of Facebook or Google Login APIs. The figure below illustrates the interface presented to users when the app is downloaded. The process of adding, browsing or requesting items is straightforward and intuitive and each task can typically be completed within a couple of minutes.

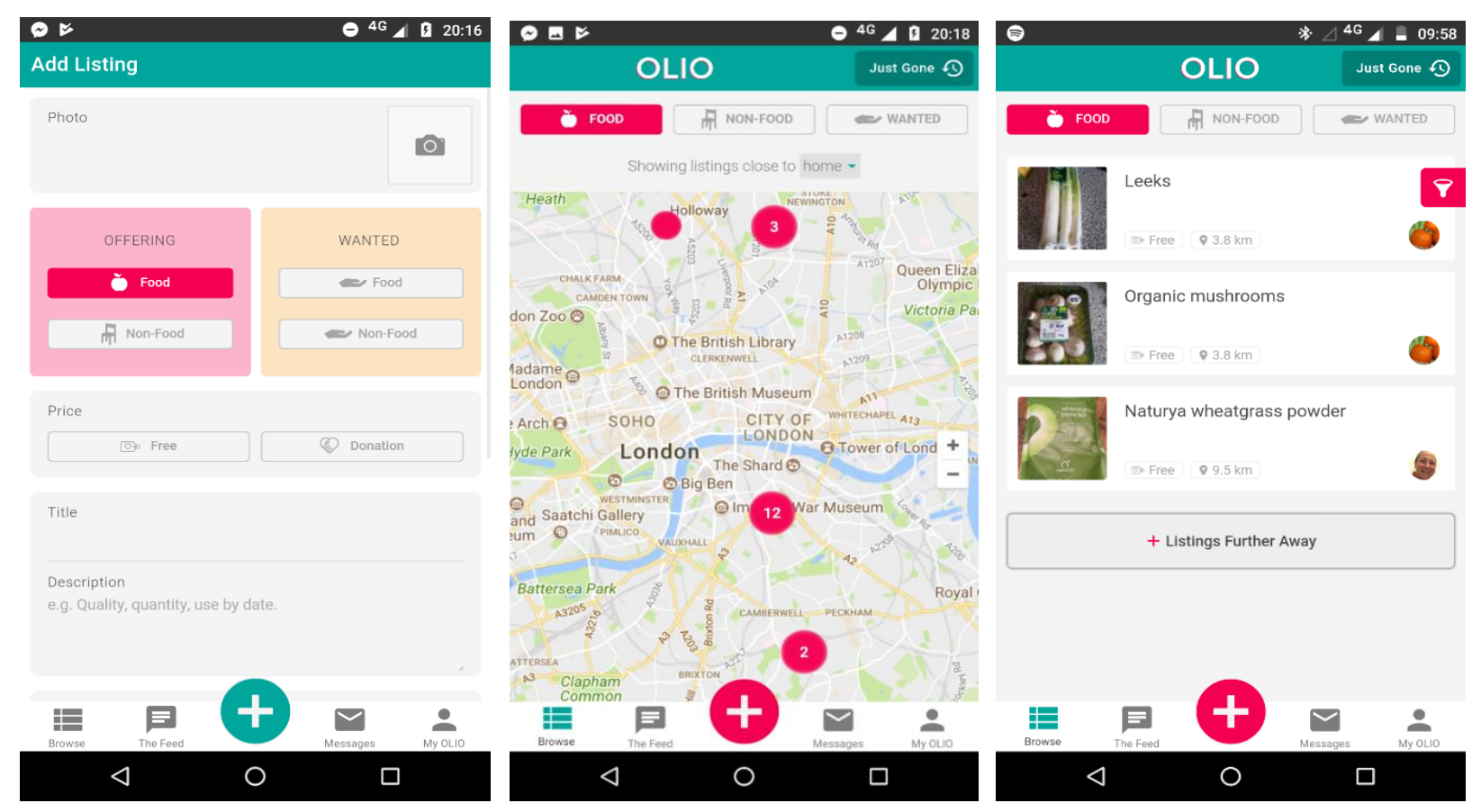

Figure 1: The interface of OLIO's mobile application used to add items, browse items nearby, and request items from other users

OLIO's platform results in multiple configurations of stakeholders, including: $\mathrm{B} 2 \mathrm{C} 2 \mathrm{C}$ where consumers purchase food from an organisation but then redistribute; $\mathrm{B} 2 \mathrm{~V} 2 \mathrm{C}$ wherein OLIO volunteers act as a trusted and vouched for intermediary, rather like a distributor company, albeit an unpaid one; and $\mathrm{C} 2 \mathrm{C}$ where consumers grow or create their own produce and then redistribute it without the intermediation of third party organisations. Lewis et al (2017) note that OLIO encourages a civic-minded digital consumerism with a commercial edge, the act of sharing leftover food is framed as a potentially transformative act for consumers and businesses alike. This provides an opportune moment to examine whether OLIO has genuinely supported the emergence of transformative social relations between organisations and consumers. 


\section{Research Approach}

The design of the study focuses on network analysis measures of a longitudinal dataset to specifically examine the following questions:

1) How do the food sharing behavioural repertoires of OLIO users vary? Here we are interested in understanding whether most users act as donors and recipients, whether users exhibit consistent behavioural patterns over time, and whether user interactions are premised on ongoing reciprocal relations with other users (as expected by long-standing food sharing theory). These data can help to explain how OLIO's use of information technology has influenced the emergence of novel supply relations (As called for by Makkonen \& Vuori, 2014).

2) How interdependent are the people sharing food as donors and recipients? Guyader (2018) suggests that future research should investigate what $\mathrm{P} 2 \mathrm{P}$ sharing providers and consumers do when they engage in collaborative consumption practices facilitated by online platforms. By examining the interdependent behaviour of users it is possible to move beyond simplistic insights generated by self-reported accounts of individual users to a more complex understanding of the situational determinants and mechanisms which enable food sharing communities.

Taken together, these questions can also help elucidate whether existing food sharing theories such as reciprocity, tolerated scrounging, or costly signalling are a sufficient theoretical lens to explain user behaviour exhibited in novel P2P food sharing systems. Both of these questions are aimed at revealing novel social arrangements between organisations and consumers. Each question is addressed empirically using network graphs of interactions between OLIO users that can illustrate patterns of exchange. Although much previous work on food sharing has focused on attitudinal perspectives through ethnography, survey or interviews, there is a clear shortcoming to these approaches in that they cannot capture food sharing behaviour at scale. The research design therefore takes historical behavioural data as the starting point and uses abductive reasoning to begin theorisation about the social arrangements that support successful food sharing. 
Although abductive reasoning has historically been resisted in the marketing discipline, the widespread availability of big data has prompted many academics to reconsider, particularly where observed behavioural data gives an unprecedented insight into the way that people act in natural settings (Hofacker et al., 2016). The limitation of such an approach is that motivation can only be inferred, but the movement from observation to theorisation is required to avoid a priori conclusions drawn from small samples of attitudinal data i.e. what people say compared to what people actually do in practice. The difficulty in conducting this type of research is gaining access to large-scale longitudinal data, but in this instance OLIO are an active partner in the research because the findings can be used to help improve the service and draw wider attention to an important social issue.

\subsection{Data collection}

The anonymised dataset initially obtained from OLIO contained items offered by users, items requested by users, and items successfully 'picked up' (obtained) by users. The records were collated by querying transaction data logged on OLIO's servers and exporting them as a .tsv file into Microsoft Excel. Each of the records showed anonymised user IDs, a timestamp, and associated latitudinal and longitudinal data which were converted into distance calculations. The transactional data contained a 10-month period from 11/03/2017 to 12/01/2018 - totalling 307 days. There are 76908 unique items listed in the dataset, 100364 unique requests for 50452 unique listings, and 54913 successful offline transactions from 39801 unique listings which involve 9054 users of the network.

\subsection{Research Methods}

The core research method is an exploratory social network analysis (de Nooy, 2018, Kadushin, 2012) using various analytical and visualisation software. The open source software named 'Gephi' was used for visualization of the OLIO network graph (See Bastian et al., 2009). UCINET and Pajek were used for network analysis (See Borgatti et al., 2002; Borgatti et al., 2013; Batagelj and Mrvar 1998). The method was divided into two key sections: (1) basic network measures to assess reciprocity; and (2) Measures to assess interdependency. Each of these are now described in turn. 


\subsubsection{Basic network measures to examine variance in behavioural repertoires of OLIO users}

Reciprocity (bidirectional edges) is analysed by examining in and out degree connections for each node and calculating the total as a proportion of all edges in the graph. Indirect reciprocity is analysed by identifying and counting all directed cycle subgraphs within the dataset $(3,4,5,6 \ldots \mathrm{n}$.), summing the total and then calculating all edges that fall on a directed cycle subgraph as a proportion of all edges in the graph. Algorithms to calculate indirect reciprocity are not widely available in network analysis software packages so an algorithm was computed manually using the software Python. In the figure shown below there is an example of one directed cycle with a depth of four people between nodes 2-35-4. In our analysis we are interested in the temporal sequence as well as directed cycles because this would provide evidence that people were actually responding to the idea of giving something in order to get something back in future from other people in the network. The search for directed cycles was therefore constrained by temporal sequence to ensure any form of indirect reciprocity was sequentially reached.

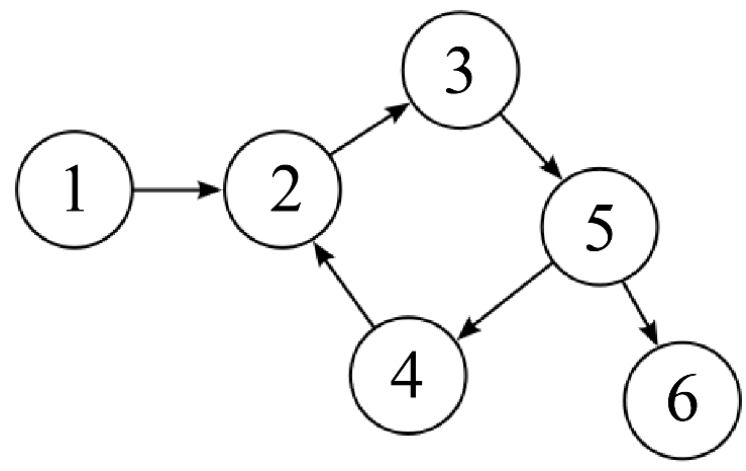

Figure 2: An example of a 4-person directed cycle

\subsubsection{Measures to assess interdependency}

Centrality measures are widely used in social network analysis for measuring the relative 'importance' of individual nodes within broader social structures (Kang et al, 2011). Centrality refers to the extent to which a node contributes to the structure of a network by virtue of its position in the network. The meaning of centrality varies depending upon the mathematical characterisation of the phenomena being studied. Typically, centrality is measured according to degree, closeness, betweeness, eigenvalue, or power measures (e.g. Bonacich, 1987). 
For the OLIO network we are interested to examine how individual users vary across in-degree (the number of edges coming into a node, in this case in-degree count illustrates being a recipient in food sharing relationships) and out-degree measures (the number of edges leaving a node, in this case outdegree count illustrates being a donor in food sharing relationships) to get a sense of behavioural repertoires and aggregate statistics, but we are also interested in the relative isolation of recipients and donors. Degree measures give no real sense of whether a person is well-placed in the network to find alternative community members with whom they can interact. Isolation is potentially a problem for users that have nobody to share food with (i.e. food wastage), but a lack of interdependence would also be a problem for users that take food disproportionately but have few sources from which they can take. If a person is persistently taking food but has few people to interact with this would indicate a disproportionate dependence in comparison to other nodes in the network.

Unlike many directed 'objects' that have been modelled using network analysis such as gossip, influence, disease, or money, food is unusual because it is perishable and suffers from 'subtractability' (if one person consumes the object other people cannot, for example if John eats an apple Martina cannot eat that same apple) and can't be possessed simultaneously by more than one person (See Ostrom, 2003). Subtractability means that many existing centrality measures offer only a limited insight when compared to non-subtractable objects. We propose that four other structural measures offer a clearer insight into dependency within the network: (1) Fragmentation; (2) Connected Components; (3); Cliques; and (4) Degree Assortativity (homophily).

Network fragmentation refers to the proportion of pairs of nodes that cannot reach each other by any means and is calculated using an algorithm by Borgatti (2006). A highly fragmented network would reveal that only a small portion of nodes fall into the central component and indicate that OLIO users are forming disparate relations, whereas a network with low fragmentation would indicate a highlyconnected central component in which most people are at least indirectly connected with each other. Further precision can be attained by calculating the number of 'strongly' or 'weakly' connected components within the graph. A component is a maximal set of nodes where every node can reach every other by some path. A 'weakly' connected component ignores the directionality of connections 
between nodes, whereas a 'strongly' connected component incorporates directionality into the measure and is thus more stringent. Both measures provide an insight into the overall cohesion of the nodes in a network and are useful for highlighting the relative proportion of isolated nodes. These measures are calculated using an algorithm created by Tarjan (1972).

Fragmentation and connected components give an insight into the broad structures present in the network, but we are also interested in understanding the interpersonal relations that have formed in the network. A clique refers to a maximally complete subgraph "in which every actor is adjacent to every other actor in the subset and it is impossible to add any more actors to the clique without violating this condition" (Borgatti et al., 2013, p.183). Cliques provide an immediate measure of whether 'communities' exist within a network and serve as a useful indicator of whether a network has managed to foster interdependent relations. If OLIO has succeeded in creating genuinely interconnected communities the presence of maximal subgraphs with nodes of more than 3 would be high. Although cliques ignore directionality they empirically demonstrate tight-knit relations between people and thus can be used to illustrate how traditional linear supply chains are being overturned.

A more nuanced measure of interpersonal relations is degree assortativity i.e. whether people who are similar to each other interact with one another (like the popular expression 'birds of a feather flock together') or whether people seek interpersonal difference in their relations. Degree assortativity gives an insight into whether people are actively seeking qualitatively different types of user in their interactions, which is useful for the OLIO network because it can give an insight into the different decision making processes and behavioural repertoires of users. In directed networks each node $i$ is characterised by an incoming $k$ in and an outgoing $k$ out degree. Assortativity is therefore defined through four degree correlation functions: in-in, in-out, out-in, and out-out (Barabási, 2016), using the Pearson correlation coefficient between the degrees found at the two ends of the same link.

\subsection{Ethics}

The dataset provided by OLIO contains information only relating to adults (aged 18 years and over) as per the terms and conditions set out with their users. Specific personal information from individual 
users was not stored or analysed. All social network data included within the study were anonymised at point of collection and only aggregate statistics were included for analysis.

\section{Results and Discussion}

The results from the longitudinal social network analysis are organised around two key aspects:

(1) the behavioural repertoires of users, based on basic network measures; and (2) interdependency between donors and recipients.

\subsection{The variance of behavioural repertoires for OLIO users: Basic network measures}

\begin{tabular}{lcc}
\hline Basic network measures & Number of cases & Percentage \\
\hline $\begin{array}{l}\text { Unique offline active users } \\
\text { (donated or received) }\end{array}$ & 9054 & $100 \%$ \\
\hline Unique donors & 6365 & $66.65 \%$ \\
\hline Unique recipients & 4177 & $46.13 \%$ \\
\hline $\begin{array}{l}\text { Users that have BOTH given and donated } \\
\text { using OLIO (Intersection donors-recipients) }\end{array}$ & 1488 & $16 \%$ \\
\hline $\begin{array}{l}\text { Number of bi-directional relations formed } \\
\text { between dyads }\end{array}$ & 848 (From 21008 dyads) & $4.04 \%$ \\
\hline
\end{tabular}

Table 1: Overall characteristics of the OLIO food-sharing network.

The analysis shows that most individuals using the OLIO platform to share food adopt the role of either donor or recipient, with a much lower number of members of the network engaging in both roles. The directed network graph below presents an overview of transactions between OLIO users and was visualised using the software Gephi. The layout algorithm used was created by Fruchterman \& Reingold (1991) and is used to visually delineate disparate interactions (distance between nodes is nonrepresentative). Despite a large degree of fragmentation of nodes visible around the periphery of the graph, there is nonetheless a large connected component notable in the centre, which manifests from interactions between the most active users. The central component includes a group of highly connected users with relatively high levels of in and out degree score. Figure 4 reveals that the clustered communities of users shown in the network graph have a clear correspondence to geography, as $76 \%$ 
of offline transactions occur within $5 \mathrm{~km}$ and $92 \%$ of transactions within $10 \mathrm{~km}$, and these are mainly within the UK.

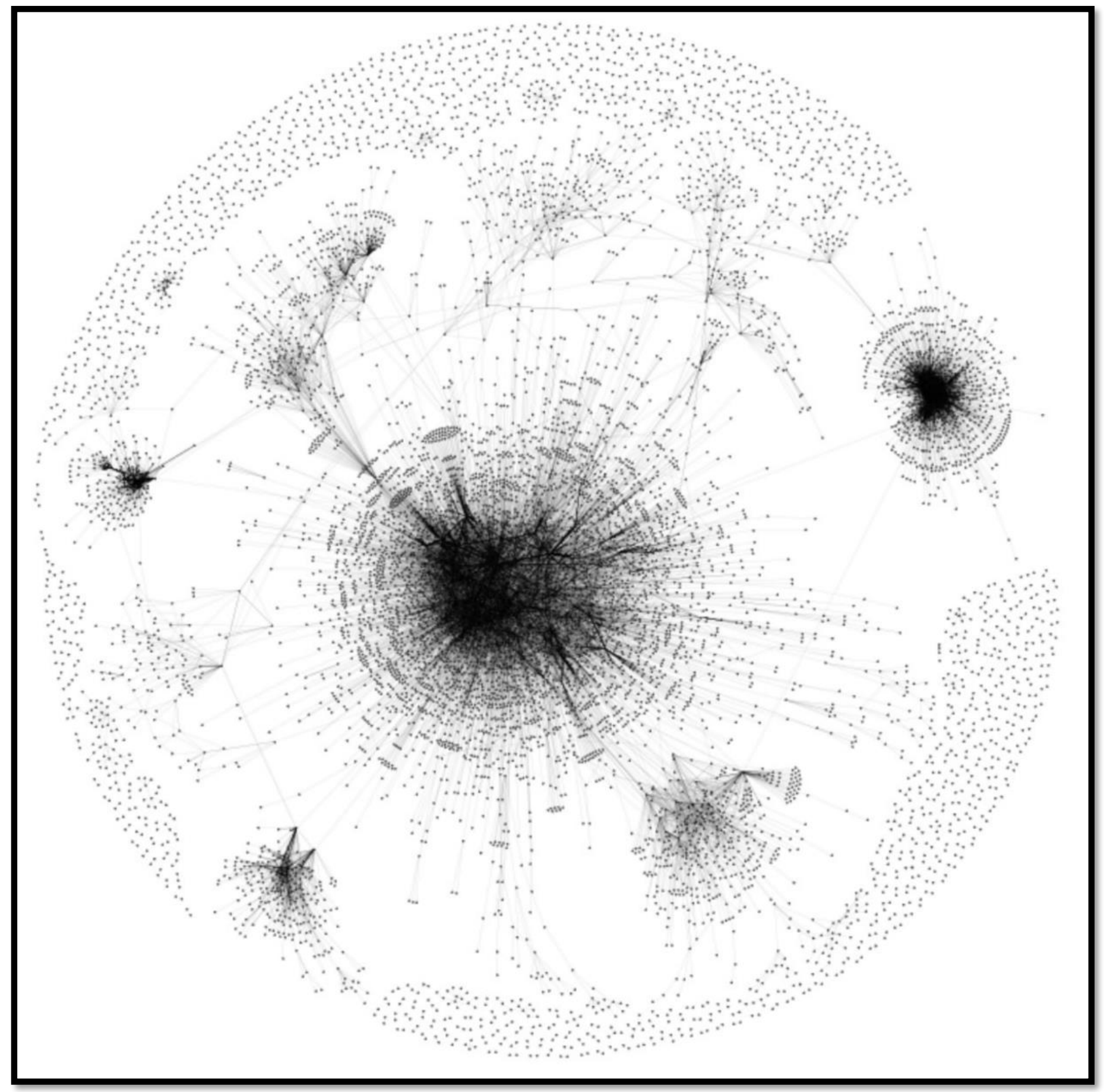

Figure 3: Directed network graph showing transactions between OLIO users. Users are depicted as nodes $(\mathrm{n}=9054)$ and transfers are depicted as edges $(\mathrm{n}=54913)$ 


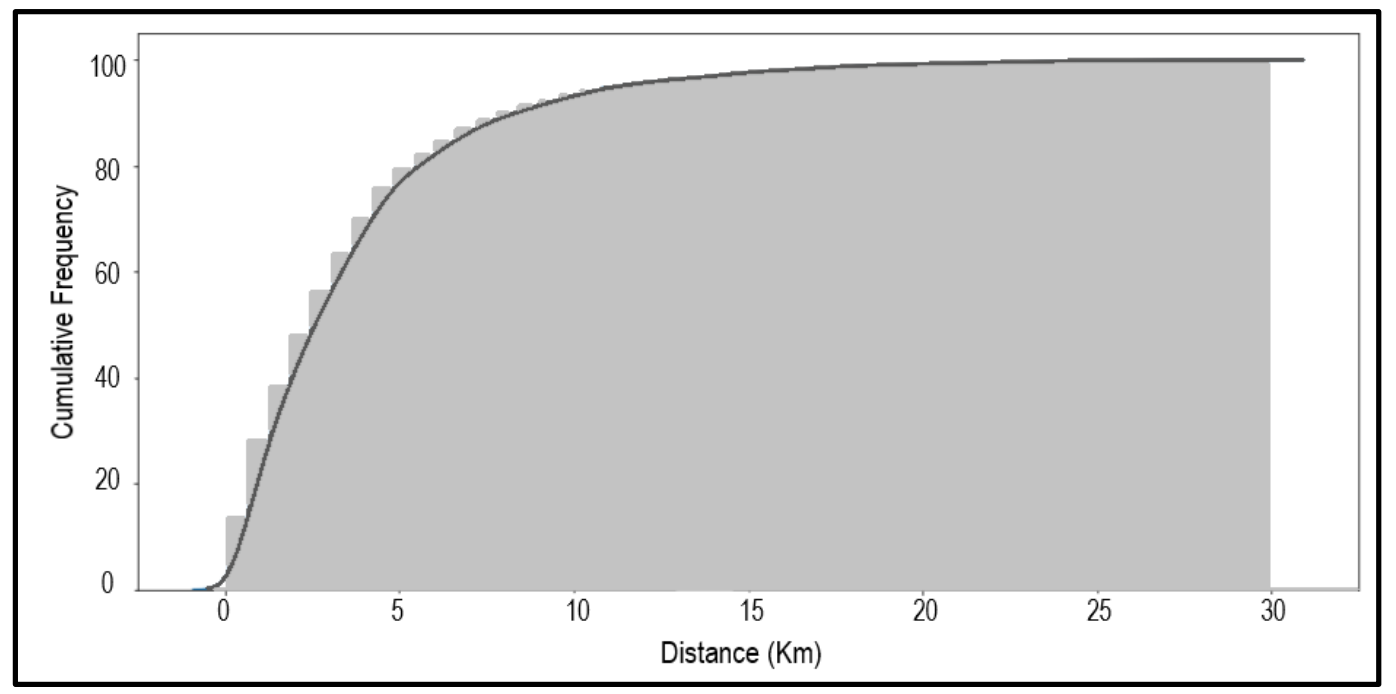

Figure 4: Cumulative frequency percentages for estimated distance travelled of successful pickups

The most immediate empirical evidence into the lack of balance in the network can be seen in the number of unique donors, number of unique recipients, and the intersection of the two. Only $16.43 \%$ of users have performed both roles, which demonstrates clearly that there is a qualitative split present in the user base between users that primarily give or take.

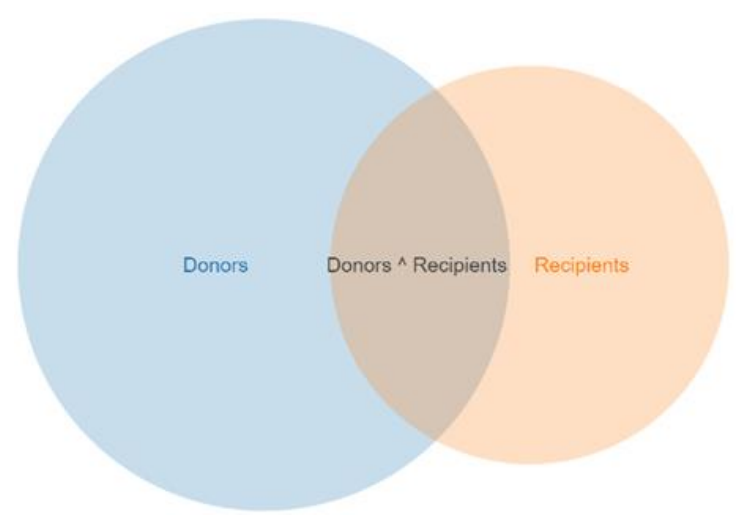

Figure 5: Representation of behavioural roles enacted by network members

This statistic fails to reveal how users use the application given an extended period of time, but it does provide convincing evidence of different behavioural roles which are being enacted. The figure below reveals the percentage of users who either only donate, only receive, or do both as a function of the number of pickups they have experienced. 


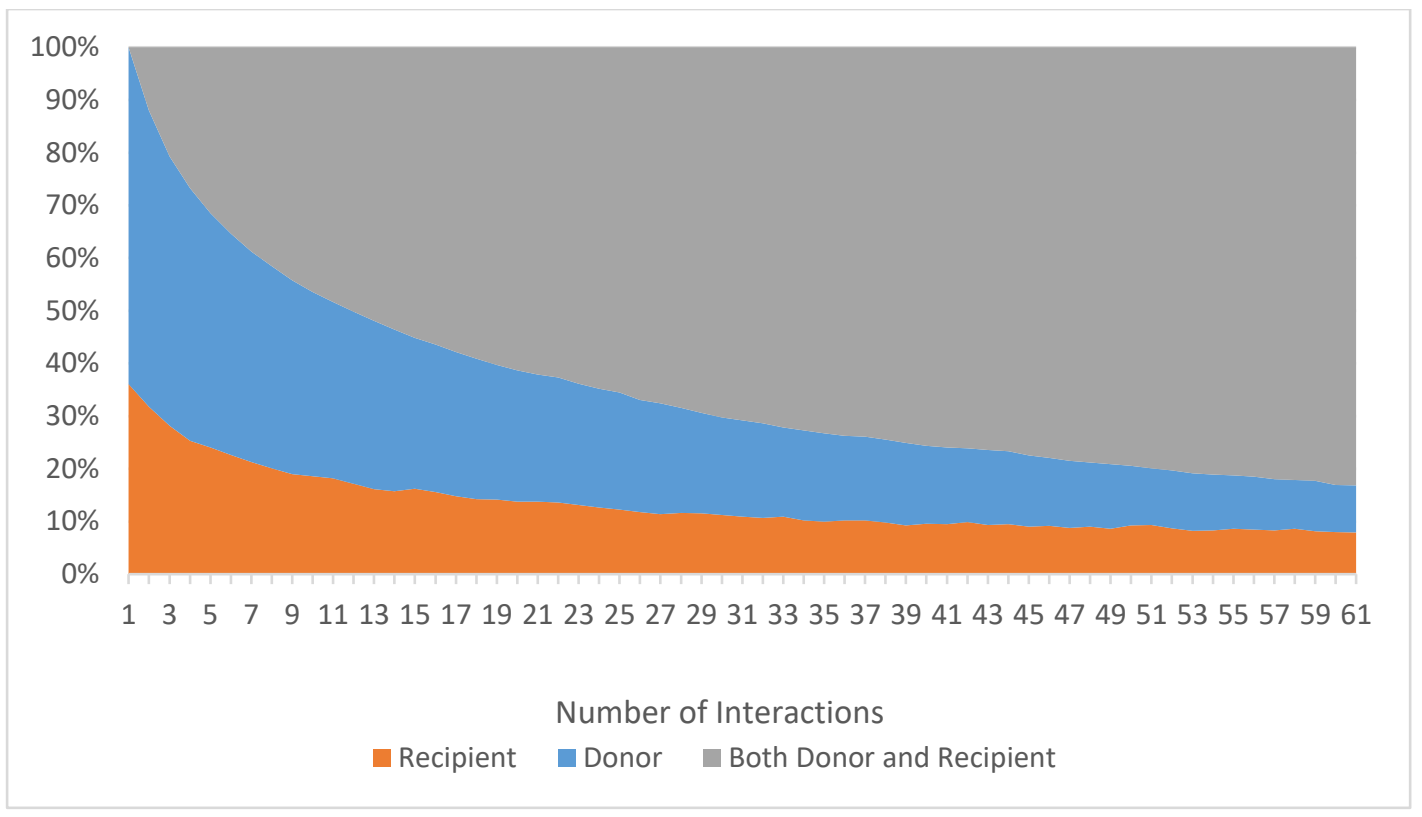

Figure 6: Percentage of users who only donate, only receive, or do both, as a function of number of successful pickups

Figures 5 and 6 reveal a stark contrast in how users initially use the system. The imbalance begins in the first interaction where the majority favour being a donor rather than a recipient. The imbalance is due to the fact that many donors give away an offering to multiple recipients, for example they may collect bread at the end of the day from a baker and distribute loaves to multiple recipients. Although users do tend towards performing both roles over time it is not until the 12 th interaction that $50 \%$ have performed both, and even after the 52nd interaction there is still nonetheless a solid core of users (20\%) that persist in only one form of behaviour. However, it is worth noting that the both category represents only $16.43 \%$ of users and the population of users at each number of interactions fall sharply. Although we cannot infer motivation from behavioural data, we can see that these users are reluctant to broaden their behavioural repertoire over time, preferring instead to enact only one behaviour. Taken as a whole the behavioural data illustrates that OLIO's network departs from the simple traditional food commodity lifecycle characterised by one-way flows from producer to consumer. This social configuration between OLIO, $3^{\text {rd }}$ party donor organisations, volunteers and consumers transforms linear food supply chains into a constellation of networked actors, each with specific values and behavioural repertoires. This preliminary finding extends existing research on the role of supplier-buyer 
relationships when using online platforms (Guyader, 2018) by showing how users interact in a P2P context enabled by digital platforms.

Bi-directional relations between dyads are relatively uncommon in the network (848 instances - 4.04\%), suggesting that approximately one in 25 relations that form on OLIO could be defined as 'reciprocal' in the loosest sense. This figure is skewed by the often one-to-many nature of donations (one donor may give away items to many different recipients) but it is nonetheless illustrative of the transformative roles of volunteers in the OLIO network who sometimes more closely resemble traditional organisations in their interactions rather than lone consumers. A more precise measure of direct reciprocity is to incorporate temporal sequence into the analysis (i.e. A gives to B then B gives to A as opposed to A gives to B repeatedly before B returns the favour). When temporal sequence is included in the analysis there was 265 instances of direct reciprocity (1.26\%), which suggests that bi-directional relations become more common after one person has repeatedly given to another rather than one-off donations.

To calculate indirect reciprocity an algorithm was written which identified time-ordered cycles as subgraphs within the overall network. In this instance, we define a time-ordered cycle where Person A shares food to person B and Person B subsequently shares food with person C who then also subsequently shares food with Person A, and thus completes a closed cycle, or in other words a circle of people 'passing on the favour' indirectly. The minimum possible chain of users participating in indirect reciprocity is 3 , but this can potentially extend throughout the entirety of the network. 75 instances of indirect reciprocity between 3 users were found. Instances of indirect reciprocity diminish from 3 users upwards until reaching a limit at a depth of 9 users (1 time-ordered cycle was found). In total 401 reciprocal cycles were found that respected time ordering, up to a depth 9 . The full results can be seen in the figure below: 


\begin{tabular}{|c|c|c|}
\hline $\begin{array}{l}\text { Time-ordered } \\
\text { cycle depth }\end{array}$ & Count & Cumulative total \\
\hline & & \\
\hline $\mathbf{2}$ & 265 & 265 \\
\hline $\mathbf{3}$ & 75 & 340 \\
\hline $\mathbf{4}$ & 29 & 369 \\
\hline $\mathbf{5}$ & 15 & 384 \\
\hline $\mathbf{6}$ & 6 & 390 \\
\hline $\mathbf{7}$ & 6 & 396 \\
\hline $\mathbf{8}$ & 4 & 400 \\
\hline $\mathbf{9}$ & 1 & 401 \\
\hline
\end{tabular}

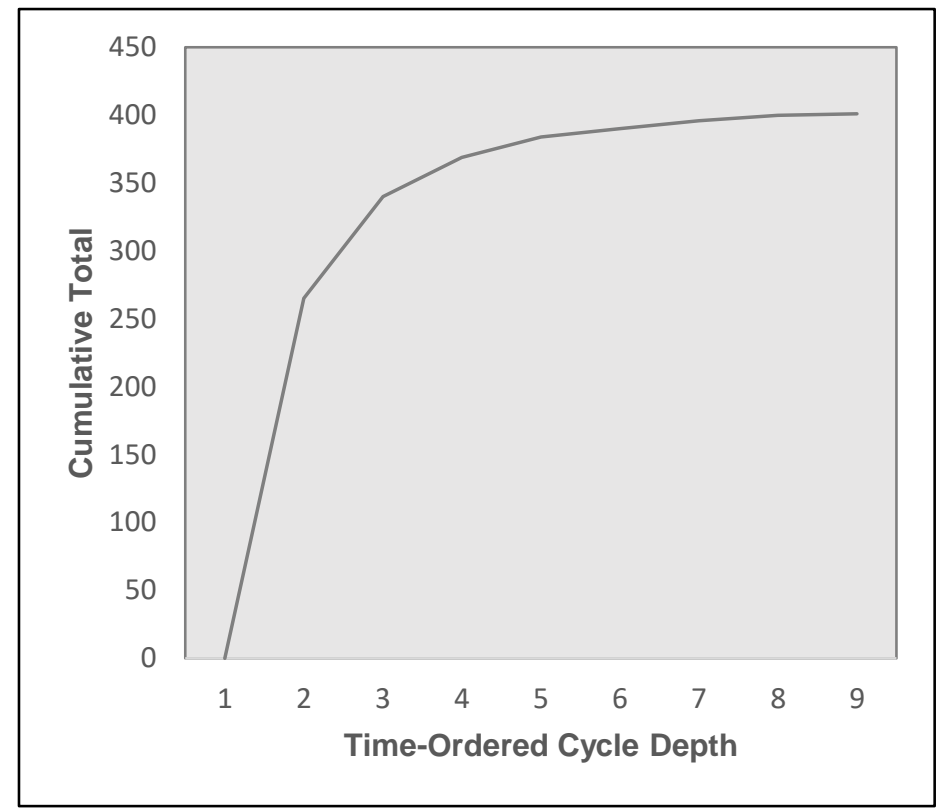

Figure 7: Indirect reciprocity statistics generated through time-ordered cycle depth searches

Only $1.26 \%$ of links were directly reciprocated at some point, but even when indirect reciprocity is included within the analysis just 401 instances of food sharing (1.90\%) were looped back at any point via a circuitous route. These results alone would directly challenge the orthodox view that food sharing can be explained through recourse to reciprocal altruism (e.g. Jaeggi \& Gurven, 2013b). But these figures actually still overinflate the claim for genuinely reciprocal behaviour. How long does the delay between two transfers have to be before it can no longer be classed as 'reciprocation? This is an issue which few researchers have addressed empirically, but it is important to recognise that if food sharing actually causes OLIO users to feel a sense of debt or obligation then a return in kind would be expected in a relatively short period of time. However an analysis of the delay between items that were directly reciprocated reveals that some gaps are months long. Figure 7 reveals that $26.04 \%$ instances of reciprocity occurred after 50 days had elapsed from the first transfer, which suggests a large portion of reciprocal acts are actually occurring due to chance rather than a feeling of interpersonal debt or obligation. These figures demonstrate that even if a small subset of users do share food with the same users as both donors and recipients, the majority of other users in the network are exhibiting different behavioural repertoires and that these roles vary widely according to occurrence, temporality, and whether a person is acting as an intermediary or not. These findings also challenge the notion of "generalised reciprocity" as a common ethos for participants in existing P2P (Guyader, 2018) and 
supply chain research (Makkonen\&Vuoni, 2014) by showing that the relationship between food donors and recipients (suppliers and buyers respectively) is not based on reciprocity .

\begin{tabular}{|c|c|}
\hline $\begin{array}{c}\text { Reciprocity } \\
\text { Timeframe }\end{array}$ & Count \\
\hline 0 to 25 days & 153 \\
\hline 25 up to 50 days & 43 \\
\hline 50 up to 75 days & 21 \\
\hline 75 up to 100 days & 11 \\
\hline 100 up to 125 days & 14 \\
\hline 125 up to 150 days & 9 \\
\hline 150 up to 175 days & 6 \\
\hline 175 up to 200 days & 3 \\
\hline 200 up to 225 days & 4 \\
\hline 225 up to 250 days & 1 \\
\hline
\end{tabular}

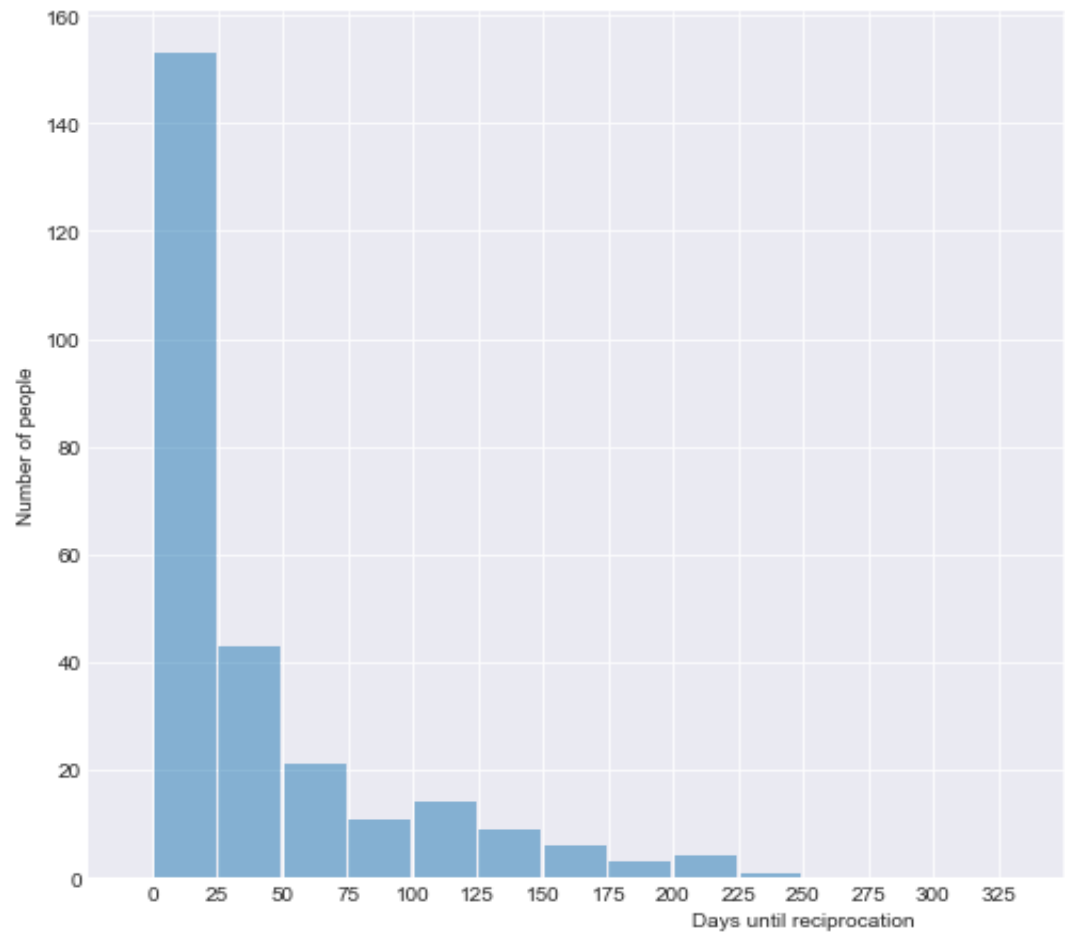

Figure 8: Delay period for directly reciprocal dyads

The social configurations formed by users illustrate how the traditional producer-consumer dichotomy is being eroded as the OLIO platform mediates the relation between organisations, volunteers and consumers $(\mathrm{B} 2 \mathrm{~V} 2 \mathrm{C})$ and consumers to consumers $(\mathrm{C} 2 \mathrm{C})$. To gain a more nuanced account of these relations we now examine interdependency measures.

\subsection{Interdependency between donors and recipients: Centrality Measures}

\begin{tabular}{lc}
\hline Network Interdependency measures & \\
\hline Average Degree (in-degree and out-degree) & 6.065 \\
\hline In-degree standard deviation & 21.705 \\
\hline Out-degree standard deviation & 64.051 \\
\hline Network Fragmentation (Borgatti, 2006) & $0.909 \%$ \\
\hline Number of Strongly Connected Components & 575 \\
\hline Number of Weakly Connected Components & 8179 \\
\hline
\end{tabular}

Table 2: Interdependency measures 
The network visualisation shown earlier clearly demonstrates that fragmentation of the network is high $-90 \%$ of pairs of nodes cannot reach each other by any means. This provides a preliminary insight into the way groups form on OLIO and is to be expected given the size of the network and that typically one person at least must travel to share food with another person (this is normally the recipient, but the meeting place is socially negotiated within the application). This is unlike many other social networks that model the directionality of friendship or gossip, which can be directed digitally without suffering from subtractability as mentioned earlier. Despite high fragmentation there are a range of varied components that have emerged in the network that are evident in the centre and around the periphery. 575 strongly connected components provides a clear indication that OLIO has already succeeded in connecting disparate groups of users in many different locations. However, when we focus on weakly connected components there are far more (8179). This finding corroborates with the previous section in that people are using the application to share food in different ways (as donors and recipients) and consequently there is often a lack of balance in donor behaviour for the average user, but there is nonetheless bi-directionality in donor behaviour across the network. This finding adds complexity to existing knowledge on buyer-supplier relationships (Makkonen\&Vuoni, 2014) by showing the behavioural repertoires of users are clearly influenced by the design of the technology that supports food sharing practices rather than being the simple result of basic motivational states.

The average degree for all users of the network (of donors and recipients) is 6.065 , with a standard deviation of 21.705 and 64.051 for in and out degree respectively. The large variance among degree provides a preliminary insight into the presence of different behavioural repertoires among the OLIO users. 

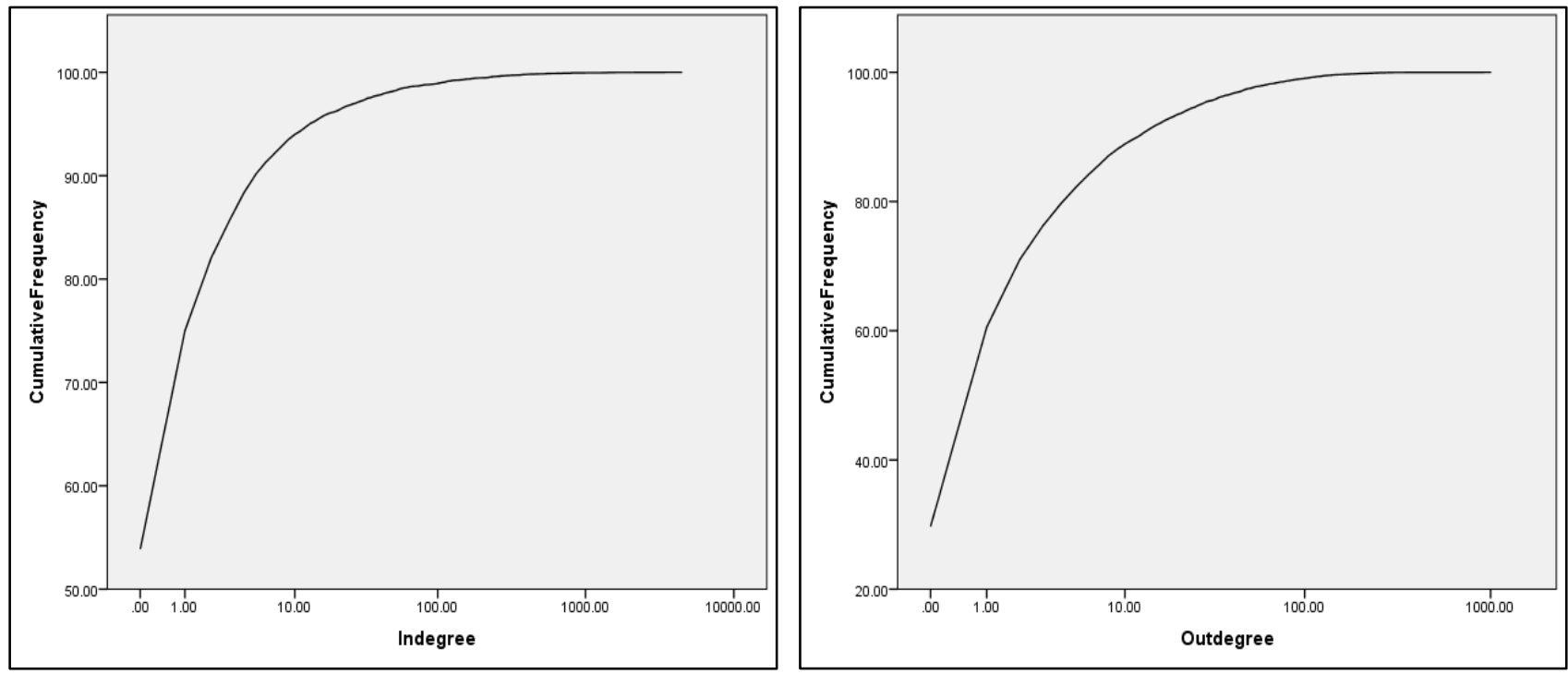

Figure 9: Cumulative Frequency Percentages for Indegree and Outdegree of OLIO users

Like most directed social networks, OLIO's network exhibits a distribution in which a relatively small percentage of users have formed a larger number of connections than the mean average user (as either donors or recipients). The core of users that use OLIO intensely to donate or receive therefore have disproportionate in and out degree scores. This suggests that not only is there a qualitative distinction in forms of donors and recipients, there is also a large variation in the way that users perform these distinct behaviours. Some users are using OLIO sporadically whereas others are voracious recipients. Although it is impossible to generalise this finding to other sharing services, the results corroborate with those found by Harvey (2016) who performed a network analysis on the sharing service Streetbank and found a similarly broad behavioural repertoire of users. Degree scores provide an insight into localised relations, but we now turn to the broader structures of interdependence that have formed within the network.

\begin{tabular}{|c|c|}
\hline Clique Size & Count \\
\hline 3 & 3688 \\
\hline 4 & 1805 \\
\hline 5 & 826 \\
\hline 6 & 415 \\
\hline 7 & 230 \\
\hline 8 & 150 \\
\hline 9 & 67 \\
\hline 10 & 9 \\
\hline 11 & 2 \\
\hline
\end{tabular}

Table 3: Clique Analysis 
The clique analysis reveals that genuinely interconnected 'communities' of users are forming in the OLIO network. Although clique data is symmetrized (ignores directionality of transactions) it nonetheless illustrates broad structural motifs in the network. Two 11-person cliques were found which demonstrates the tight-knit relations present between the most active users (see table 3). This is a remarkable accomplishment on the part of OLIO's mobile application design, which has enabled previously disparate groups of people to mobilise efficiently around a common cause. Despite fragmentation shown around the periphery of the graph there are nonetheless hubs which have proliferated rapidly, this is largely a consequence of volunteers who distribute multiple goods to multiple users. Highly active distributors and recipients serve as focal points around which localised food sharing networks have emerged.

The transactions in the dataset demonstrate that there is demonstrable variance in the way users conceptualise and act to reduce food waste. A further insight into how users rationalise their decisions to participate can be gleaned from an analysis of degree assortativity within the network.

\begin{tabular}{|c|c|}
\hline Assortativity Measure & Correlation Coefficient \\
\hline Input-Input Degree Assortativity & -0.00385 \\
\hline Input-Output Degree Assortativity & 0.01757 \\
\hline Output-Input Degree Assortativity & 0.02645 \\
\hline Output-Output Degree Assortativity & 0.00650 \\
\hline
\end{tabular}

Table 3: Four measures of degree assortativity

The assortativity results provide further evidence that the network contains a broad range of behavioural repertoires. The results show that the network has an extremely weak assortativity and tends towards a neutral correlation coefficient across all input-output, output-input, and output-output directed measures. Input-input degree shows an extremely weak disassortativity, but again tends towards a neutral status. In an assortative network we would expect to see highly active donors interacting with each other, but this is not the case. Instead, the network is fragmented and within each component there are typically a range of users varying in (1) their preferred donor or recipient behaviour; and (2) the frequency with which they use the service. Consequently the OLIO network has succeeded in levelling the relations 
between $\mathrm{B} 2 \mathrm{C}$ and $\mathrm{C} 2 \mathrm{C}$ such that food sharing has become much more anarchistic in practice than traditional food supply chains could ever allow. Food sharing practices between users are clearly not just similar actors interacting (based on usage frequency or preference of behaviour). The lack of clear assortativity /disassortativity suggests that even though there is a behavioural split for many users, the network isn't just volunteer handouts to a needy poor. Volunteers too are recipients (largely because they generally experience the application first as users before subsequently volunteering to help others, and this is also the case between active donors (who don't only give to active recipients, they also give to each other progressively more over time.) The assortativity results indicate that the average user interacts roughly an equal amount of times with users that are both similar and dissimilar to themselves. Therefore, we have a network which exhibits anarchistic food sharing practices characterised by bidirectional (albeit not balanced or reciprocal) flows between users at an individual user and volunteer level.

The conclusion is thus that no one stakeholder group in the OLIO network is solely responsible for a linear 'flow' of food as seen in traditional supply chains. The results can be seen as a direct response to Guyader's (2018) call for a deeper understanding of what peer service providers and consumers do when they engage in collaborative consumption practices facilitated by online platforms.

\section{Conclusion}

\subsection{Theoretical contribution}

The present longitudinal study contributes to the understanding of food sharing in three different ways. First, the use of network measures demonstrates that most food sharing transactions were not based on reciprocity, as the majority of individuals played only the role of the donor or the recipient. These findings challenge previous claims that food sharing between non-kin is based on generalised reciprocity (Pouffe, 2008; Guyader, 2018). They also shed light on the role of buyer-supplier relationships in the context of collaborative platforms, an area of research that according to Makkonen \& Vuori (2014) has focused on operational issues and overlooked the role of relationships and networks. Also, our findings extend existing knowledge on the impact of digital technologies on relationships beyond mainstream B2C exchanges and the B2B context explored by Pagani \& Pardo (2017). 
Second, interdependence measures indicate the supply chains between specific groups of donors and recipients are becoming increasingly fragmented as organisations, volunteers and consumers all mediate their behaviour through peer-to-peer networks. This suggests that 'point of consumption' within food supply chains is gaining increased strategic importance, not just for redistributive platforms, but also for traditional retailers who have historically focused on 'point of origin' and 'point of sale' as the major determinants of marketing strategy (Grant, 2012). The current study expands understanding on the structure of networks where P2P interactions happen, an area that lacks research in this type of collaborative consumption (Guyader, 2018).

Third, the structure and technology created by OLIO is more than a contextual detail, it is a determining factor for sharing to take place. The role of volunteers and commercial donors inevitably have a powerful effect on the anatomy of the network. We believe managerial structure and technological design will significantly affect the nature of exchange and reciprocation in any similar sharing or redistribution platform. The four long-standing food sharing theories presented at the beginning of the paper are inadequate to explain the form of food sharing witnessed in the OLIO network. More crucially the results challenge the assumption that we can readily generalise about the anatomy of sharing in the digital era (since a key determinant is the design of the $\mathrm{P} 2 \mathrm{P}$ platform). This is not a trivial conclusion and it raises an important methodological point: If the anatomy and manifestation of the long-standing elements of sharing (e.g. reciprocation) are fluid and subordinate to the platform and managerial structure, then descriptive forms of analysis such as social network analysis are essential for scholarly insight and managerial decision making alike. Descriptive analytics must be deployed in order to understand the anatomy of the network. At a methodological level, this paper adopts a network analysis as a novel approach to understand online food sharing platforms. This expands existing conceptual research (Kumar et al., 2018) and empirical studies that employed mostly case studies involving indepth interviews (Makkonen \& Vuori, 2018; Pagani \&Pardo, 2017) and netnography (Guyander, 2018; Scaraboto, 2015). The results challenge existing theories and widely-held assumptions about how P2P sharing networks are used. Olio, like other P2P sharing networks, would be relying on some potentially very misleading assumptions without such insights. 


\subsection{Implications for practitioners and policy makers}

Food sharing is changing. $\mathrm{B} 2 \mathrm{C} 2 \mathrm{C}, \mathrm{B} 2 \mathrm{~V} 2 \mathrm{C}$, and $\mathrm{C} 2 \mathrm{C}$ relations all look set to increase in the future as a growing number of food supply chain stakeholders tackle the scourge of food surplus. The finding that OLIO's network is neither strongly assortative or disassoratative indicates the presence of multidirectional flows between multiple stakeholders. Alternative food networks are therefore transformative because they dissolve traditional linear flow of food between producers and consumers. The implication for businesses is that food surplus redistribution is now widely seen as a moral obligation to support economic and environmental justice, not just as an inconsequential corporate social responsibility gimmick. Policymakers should recognise that the OLIO network provides compelling empirical evidence that food waste and food sharing can be tackled imaginatively without relying solely on inflexible B2B supply chains. If the UK government introduces legislation to prohibit supermarkets and grocers from disposing food surplus (as has already happened in France), then it is likely that the most effective solution will be to create other food sharing platforms, syndicates, or cooperatives that can manage the competing demands of multiple stakeholders and unusual supply chains. Though legislative change would potentially affect shopping behaviour (e.g. by encouraging consumers to wait until supermarkets discard food rather than purchasing it directly) consumers are likely to be also influenced by whether food is collected from a supermarket centrally, or whether food distribution is decentralised away from the place of sale (as is normally the case after OLIO volunteers collect food).

As more food surplus becomes managed through applications there is an opportunity for policymakers to work with organisations to improve (1) the accounting of food waste, and (2) the identification of vulnerable people experiencing food hardship. If OLIO, like other systems that enable donations or other forms of altruistic sharing, can calculate a dependency index (i.e. what proportion of the network are dependent on other members of the network) this could give a profound insight into how macroeconomic policy is affecting the food consumption habits of consumers. Dependency statistics could be used to help inform governmental policy at a local and national level and lend further empirical support to the alternative food network movement. 


\section{Limitations and future research}

The study reported in this article is limited in a number of ways: there is limited insight into the demographic information of the sample; the dataset does not distinguish explicitly between volunteers and other users; the network analysis involves only one alternative food network (because many users may be part of multiple networks); and there is no way to account for users who may have met online, but then taken their relationship offline and thus circumnavigated the observed behavioural data. All of these limitations would benefit from further scrutiny in future to account for how and why people begin to use food sharing applications and sustain their behaviour over time.

As an extension to this study, the area of food sharing would benefit from a qualitative understanding of the motivations to share for those members of the network who only operate as donors, only as recipients and as both (i.e. donor and recipient), as well as their perceptions of OLIO as a platform for food sharing compared to other off-line alternatives. Future research should also examine the socioeconomic status of technology-assisted food sharing donors, volunteers, and recipients. These demographics are obscure and there are no reliable statistics available on the number of people in food poverty who may be turning to services such as OLIO. One further area of serious consequence is whether people feel the same stigma reported by the users of foodbanks (Garthwaite, 2016b) when using food sharing applications. If sharing is an explicitly social activity done for a collaborative purpose i.e. avoiding food waste, then the pressure felt by recipients may diminish and allow them to feel free to partake food when offered without feeling indebtedness, shame, fear or embarrassment. This of course does not tackle the underlying systemic causes of foodbank usage such as inequity and inequality, but it may help to turn recipients into active participants who are not merely passive beneficiaries of benevolent donors, but are instead collaborators working to eliminate food waste and poverty (as has been reported in foodbanks - Garthwaite, 2017). A cynic may see this as neoliberal solutionism, but regardless of the socio-economic status of food sharing application users, encouraging less food waste is an unequivocally positive outcome.

Finally, as with so much of goods and services shared online, there are no reliable approximations of the sum total of financial value of goods exchanged. This blind spot represents a huge issue for 
managers and policymakers as the return on investment for policy is difficult to quantify, yet these types of service demonstrably offer real and significant value for hundreds of thousands of people. 


\section{References}

APPIHUK (2014), Feeding Britain: A Strategy for Zero Hunger in England, Wales, Scotland and Northern Ireland. London, UK: The Children's Society. (accessed February 03 ${ }^{\text {rd }}, 2018$ ), [available at: https://foodpovertyinquiry.files.wordpress.com/2014/12/food-pov erty-feeding-britain-final.pdf]

Barabási, A.L. (2016) Network science. Cambridge university press.

Baron, S., Patterson, A., Maull, R. \& Warnaby, G., (2018). Feed people first: A service ecosystem perspective on innovative food waste reduction. Journal of Service Research, 21(1), 135-150.

Bastian, M., Heymann, S. \& Jacomy, M. (2009) 'Gephi : An Open Source Software for Exploring and Manipulating Networks', in Proceedings of International AAAI Conference on Weblogs and Social Media.

Batagelj, V. and Mrvar, A., 1998. Pajek-program for large network analysis. Connections, 21(2), pp.4757.

Birch, L.L. \& Billman, J., (1986). Preschool children's food sharing with friends and acquaintances. Child Development, 387-395.

Bloom, J., (2010). American wasteland: How America throws away nearly half of its food (and what we can do about it). Da Capo Lifelong Books. Vancouver

Bonacich, P., (1987). Power and centrality: A family of measures. American journal of sociology, 92(5), $1170-1182$.

Borgatti, S.P., Everett, M.G. \& Freeman, L.C. (2002). Ucinet 6 for Windows: Software for Social Network Analysis. Harvard, MA: Analytic Technologies. Available from: https://s3.amazonaws.com/academia.edu.documents/31584161/Ucinet_6_Users_Guide.pdf?AWSAcc essKeyId=AKIAIWOWYYGZ2Y53UL3A\&Expires $=1516028068 \&$ Signature $=$ jbqg2Z3HgpMgMnnU $\underline{\text { s4JyCJsxC\%2Fc\%3D\&response-content- }}$ disposition=inline\%3B\%20filename\%3DUcinet_6_Users_Guide.pdf [Last accessed 15/01/18] 
Borgatti, S. P., Everett, M. G., \& Johnson, J. C. (2013). Analyzing Social Networks. London: SAGE Publications

Borgatti, S.P., (2006). Identifying sets of key players in a social network. Computational \& Mathematical Organization Theory, 12(1), 21-34.

Botsman, R. and Rogers, R. (2010). What's Mine Is Yours: How Collaborative Consumption is Changing the Way We Live. HarperCollins Business

Breitsohl, J., Kunz, W. H. and Dowell, D. (2015) 'Does the Host Match the Content? A Taxonomical Update on Online Consumption Communities., Journal of Marketing Management 31 (9-10): 10401064.

Brown, G.R., 2004. Tolerated scrounging in nonhuman primates. Behavioral and Brain Sciences, 27(4), pp.562-563.

Bucher, E.,Fieseler, C. and Lutz., C (2016) 'What's Mine Is Yours (for a Nominal Fee)—Exploring the Spectrum of Utilitarian to Altruistic Motives for Internet-Mediated Sharing.' Computers in Human Behavior 62, 316-326.

Buzby, J.C. \& Hyman, J., 2012. Total and per capita value of food loss in the United States. Food Policy, 37(5), 561-570.

Carrigan, M., (2017). Revisiting 'The Myth of the Ethical Consumer': why are we still not ethical shoppers? Journal of Consumer Ethics 1(1)11-21.

Ciaghi, A. \& Villafiorita, A., (2016), September. Beyond food sharing: Supporting food waste reduction with ICTs. In Smart Cities Conference (ISC2), 2016 IEEE International ( 1-6). IEEE.

Cicatiello, C., Franco, S., Pancino, B. \& Blasi, E., (2016). The value of food waste: An exploratory study on retailing. Journal of Retailing and Consumer Services, 30, 96-104.

Clear, A.K., Comber, R., Friday, A., Ganglbauer, E., Hazas, M. \& Rogers, Y., (2013), September. Green food technology: UbiComp opportunities for reducing the environmental impacts of food. 
In Proceedings of the 2013 ACM conference on Pervasive and ubiquitous computing adjunct publication (553-558). ACM.

Davies, A.R., Edwards, F., Marovelli, B., Morrow, O., Rut, M. \& Weymes, M., (2017). Making visible: Interrogating the performance of food sharing across 100 urban areas. Geoforum, 86, 136-149.

De Nooy, W., Mrvar, A. and Batagelj, V., (2018) Exploratory social network analysis with Pajek. Cambridge University Press.

Edwards F. (2016). Alternative Food Networks. In: Thompson P., Kaplan D. (eds) Encyclopedia of Food and Agricultural Ethics. Springer, Dordrecht.

Enloe, J., (2003). Food sharing past and present: archaeological evidence for economic and social interactions. Before Farming, 2003(1), pp.1-23.

Falcone, P.M. \& Imbert, E., (2017). Bringing a Sharing Economy Approach into the Food Sector: The Potential of Food Sharing for Reducing Food Waste. In Food Waste Reduction and Valorisation (197214). Springer, Cham.

Farr-Wharton, G., Foth, M. \& Choi, J.H.J., (2014a). Identifying factors that promote consumer behaviours causing expired domestic food waste. Journal of Consumer Behaviour, 13(6), 393-402.

Farr-Wharton, G., Choi, J.H.J. \& Foth, M., (2014b). December. Food talks back: exploring the role of mobile applications in reducing domestic food wastage. In Proceedings of the 26th Australian Computer-Human Interaction Conference on Designing Futures: the Future of Design (352-361). ACM.

Fehr, E. \& Fischbacher, U., (2003). The nature of human altruism. Nature, 425 (6960), 785-791.

Fruchterman, T. M. J., \& Reingold, E. M. (1991). Graph Drawing by Force-Directed Placement. Software: Practice and Experience, 21(11),1129-1164.

Ganglbauer, E., Fitzpatrick, G. \& Comber, R., (2013). Negotiating food waste: Using a practice lens to inform design. ACM Transactions on Computer-Human Interaction (TOCHI), 20(2), 11. 
Ganglbauer, E., Fitzpatrick, G., Subasi, Ö. \& Güldenpfennig, F., (2014). Think globally, act locally: a case study of a free food sharing community and social networking. In Proceedings of the 17th ACM conference on Computer supported cooperative work \& social computing (911-921).

Garthwaite, K., (2016a). Hunger pains: life inside foodbank Britain. Policy Press.

Garthwaite, K., (2016b). Stigma, shame and'people like us': an ethnographic study of foodbank use in the UK. Journal of Poverty and Social Justice, 24(3), 277-289.

Garthwaite, K., (2017) 'I feel I'm Giving Something Back to Society': Constructing the 'Active Citizen'and Responsibilising Foodbank Use. Social Policy and Society, 16(2), pp.283-292.

Goodman, D., DuPuis, E.M. \& Goodman, M.K., (2012). Alternative food networks: Knowledge, practice, and politics. Routledge.

Goody, J., (1982). Cooking, cuisine and class: a study in comparative sociology. Cambridge University Press.

Graeber, D., (2014) Debt-updated and expanded: the first 5,000 years. Melville House.

Grant, D.B. (2012). Logistics Management. Pearson Education, Harlow, UK.

Gurven, M. (2004) To give and to give not: the behavioral ecology of human food transfers. Behavioral and Brain Sciences, 27(4), pp.543-559.

Guyader, H. (2018). No One Rides for Free! Three Styles of Collaborative Consumption. Journal of Services Marketing, https://doi.org/10.1108/JSM-11-2016-0402

Hann, C., (2006) 'The gift and reciprocity: perspectives from economic anthropology' Handbook of the economics of giving, altruism and reciprocity, 1,.207-223.

Harvey, J. (2016) An economic anthropology of computer-mediated non-monetary exchange in England (Doctoral dissertation, University of Nottingham) 
Harvey, J., A. Smith, \& D. Golightly. (2017). Giving and Sharing in the Computer-Mediated Economy. Journal of Consumer Behaviour 16.(4),363 - 71.

Harvey, J., Smith, A. and Golightly, D., (2018). 'Online Technology as a Driver of Sharing'. The Rise of the Sharing Economy: Exploring the Challenges and Opportunities of Collaborative Consumption, p.75.

Hegmon, M., (1991). The risks of sharing and sharing as risk reduction: Interhousehold food sharing in egalitarian societies. Between bands and states, 9, 309-329.

Hellwig, K., F. Morhart, F. Girardin, and M. Hauser. (2015) 'Exploring Different Types of Sharing: A Proposed Segmentation of the Market for 'Sharing' Businesses.' Psychology \& Marketing 32 (9): 891906.

Monahan, S. T., \& Hu, M. (2015). Sharing Supply Chain Data in the Digital Era. MIT Sloan Management Review, 57(1), 95.

Hofacker, C.F., Malthouse, E.C. \& Sultan, F. (2016).Big data and consumer behavior: Imminent opportunities. Journal of Consumer Marketing, 33(2), 89-97.

Ingold, T.,(1986) The appropriation of nature: essays on human ecology and social relations. Manchester University Press.

Jaeggi, A.V. \& Gurven, M., (2013a). Natural cooperators: food sharing in humans and other primates. Evolutionary Anthropology: Issues, News, and Reviews, 22(4), 186-195.

Jaeggi, A.V. \& Gurven, M., (2013b). Reciprocity explains food sharing in humans and other primates independent of kin selection and tolerated scrounging: a phylogenetic meta-analysis. Proceedings of the Royal Society of London B: Biological Sciences, 280(1768), 20131615.

Jaeggi, A.V. \& Van Schaik, C.P., (2011). The evolution of food sharing in primates. Behavioral Ecology and Sociobiology, 65(11), 2125.

Kadushin, C. (2012) Understanding Social Networks: Theories, Concepts and Findings. Oxford University Press 
Kang, U., Papadimitriou, S., Sun, J. \& Tong, H., (2011). Centralities in large networks: Algorithms and observations. In Proceedings of the 2011 SIAM International Conference on Data Mining (119-130). Society for Industrial and Applied Mathematics.

Kaplan, H. \& Gurven (2005). The natural history of human food sharing and cooperation: a review and a new multi-individual approach to the negotiation of norms. In Moral sentiments and material interests: The foundations of cooperation in economic life, 75-113. Edited by Gintis, H.,..Bowles, S ,.Boyd, R \& Fehr, E., MIT Press

Kumar, V., Lahiri, A. \& Dogan, O.B., (2018). A strategic framework for a profitable business model in the sharing economy. Industrial Marketing Management. https://doi.org/10.1016/j.indmarman.2017.08.021

Lamberton, C. P., and R. L. Rose. (2012) 'When Is Ours Better Than Mine? A Framework for Understanding and Altering Participation in Commercial Sharing Systems.' Journal of Marketing 76 (4): 109-125.

Lansley, S. \& Mack, J., (2015). Breadline Britain: The rise of mass poverty. Oneworld Publications.

Lewis, T (2017).In Digital food activism. edited by Schneider, T., Eli, K., Dolan, C. \& Ulijaszek, S. Routledge

Lim, V., Funk, M., Marcenaro, L., Regazzoni, C. \& Rauterberg, M., (2017). Designing for action: An evaluation of Social Recipes in reducing food waste. International Journal of Human-Computer Studies, 100, 18-32.

Macik, M., Kutikova, A., Mikovec, Z. \& Slavik, P., (2015). GraFooSha: Food sharing for senior users. In Cognitive Infocommunications (CogInfoCom), 2015 6th IEEE International Conference on ( 267272). IEEE.

Makkonen, H. \& Vuori, M. (2014). The Role of Information Technology in Strategic Buyer-Supplier Relationships. Industrial Marketing Management, 43, 1053-1062. 
Martin, C.J., (2016). The sharing economy: A pathway to sustainability or a nightmarish form of neoliberal capitalism?. Ecological Economics, 121, 149-159.

Matacena, R. (2016) Linking alternative food networks and urban food policy: a step forward in the transition towards a sustainable and equitable food system?. International Review of Social Research, 6(1), pp.49-58.

Mourad, M., (2016). Recycling, recovering and preventing "food waste": competing solutions for food systems sustainability in the United States and France. Journal of Cleaner Production, 126, 461-477.

OLIO (2018) About page [Online] Available at: https://OLIOex.com, Date Accessed: 31/01/2018

Ostrom, E.( 2003) ‘How Types of Goods and Property Rights Jointly Affect Collective Action.' Journal of AQ20 Theoretical Politics 15 (3): 239-70

Pagani, M. \& Pardo, C., (2017). The impact of digital technology on relationships in a business network. Industrial Marketing Management, 67, 185-192.

Peterson, N., (1993). Demand sharing: reciprocity and the pressure for generosity among foragers. American anthropologist, 95(4), 860-874.

Pouffe, C.R. (2008). Examining 'Peer-to-Peer' (P2P) systems as consumer-to-consumer (C2C) Exchange. European Journal of Marketing, 42(11/12), 1179-1202.

Pryor, F.L. and Graburn, N.H., (1980)' The myth of reciprocity'. In Social exchange (215-237). Springer US.

Quested, T.E., Parry, A.D., Easteal, S. and Swannell, R., (2011) Food and drink waste from households in the UK. Nutrition Bulletin, 36(4), pp.460-467.

Sahlins, M. (1979) Stone Age Economics, Chicago: Aldine-Atherton.

Scaraboto, D. (2015) 'Selling, Sharing, and Everything In Between: The Hybrid Economies of Collaborative Networks.' Journal of Consumer Research 42 (1): 152-176.

Stevens, J.R. \& Gilby, I.C., (2004). A conceptual framework for nonkin food sharing: timing and currency of benefits. Animal Behaviour, 67, 603-614. 
Schor, J., and C. Fitzmaurice. (2015) 'Collaborating and Connecting: The Emergence of the Sharing Economy.' In Handbook of Research on Sustainable Consumption, edited by Lucia Reisch and John Thogersen. 410-425. Cheltenham, UK: Edward Elgar.

Tarjan, R. (1972) Depth-First Search and Linear Graph Algorithms, in SIAM Journal on Computing 1 (2): $146-160$

Trivers, R.L., (1971). The evolution of reciprocal altruism. The Quarterly Review of Biology, 46(1), 3557.

Trussell Trust (2017) Early Warnings: Universal Credit and Foodbanks [Online] Available at: https://www.trusselltrust.org/wp-content/uploads/sites/2/2017/04/Early-Warnings-Universal-Creditand-Foodbanks.pdf, Last Accessed: 01/03/2018

Watkins, R., J. Denegri-Knott, and M. Molesworth. (2016) 'The Relationship between Ownership and Possession: Observations from the Context of Digital Virtual Goods.' Journal of Marketing Management 32, 44-70.

Widlok, T. (2017.) Anthropology and the Economy of Sharing. Routledge. 